\title{
Metode Brown's Double Exponential Smoothing dalam Peramalan Laju Inflasi di Indonesia
}

(Brown's Double Exponential Smoothing Method in Forecasting the Inflation Rate in Indonesia)

\author{
Dini Purwanti ${ }^{1}$ *, Joko Purwadi ${ }^{2}$ \\ Matematika, Universitas Ahmad Dahlan, Jalan Ring Road Selatan, Tamanan, Bantul, Daerah Istimewa \\ Yogyakarta, 55191 \\ E-mail: dinipurwanti90@gmail.com \\ * Corresponding Author
}

\begin{tabular}{|c|c|}
\hline ARTICLE INFO & ABSTRACT \\
\hline \multirow[t]{3}{*}{$\begin{array}{l}\text { Kata Kunci } \\
\text { Brown's } \\
\text { Double Exponential } \\
\text { Smoothing } \\
\text { Peramalan } \\
\text { Time Series } \\
\text { Keywords } \\
\text { Brown's } \\
\text { Double Exponential } \\
\text { Smoothing } \\
\text { Forecasting } \\
\text { Time Series }\end{array}$} & $\begin{array}{l}\text { Penelitian ini membahas tentang metode analisis runtun waktu (time series), } \\
\text { metode yang digunakan yaitu Brown's Double Exponential Smoothing. } \\
\text { Penelitian ini bertujuan untuk menjelaskan penerapan metode Brown's } \\
\text { Double Exponential Smoothing dalam peramalan laju inflasi di Indonesia, } \\
\text { mengetahui nilai parameter optimum dan mengetahui tingkat akurasi dari } \\
\text { hasil peramalan. Penelitian ini mengambil data inflasi dari website resmi } \\
\text { Bank Indonesia. Langkah-langkah peramalan menggunakan metode Brown's } \\
\text { yaitu menentukan nilai parameter optimum, menghitung nilai pemulusan } \\
\text { tunggal (single smoothing), menghitung nilai pemulusan ganda (double } \\
\text { smoothing), menghitung nilai konstanta pemulusan, menghitung nilai } \\
\text { koefisien trend, kemudian melakukan peramalan. Berdasarkan perhitungan } \\
\text { pada metode Brown's diperoleh nilai parameter optimum yaitu alpha ( } \alpha \text { ) } \\
\text { sebesar 0,9 dengan nilai MAPE sebesar 10,607\%. Dari perhitungan } \\
\text { peramalan menggunakan metode Brown's diperoleh nilai kesalahan/eror yaitu } \\
\text { MAPE sebesar } 10,607 \% \text { yang berarti bahwa metode Brown's mempunyai } \\
\text { kemampuan yang baik dalam peramalan sesuai dengan kriteria MAPE. }\end{array}$ \\
\hline & $\begin{array}{l}\text { This study discusses the method of time series analysis(timeseries), the method } \\
\text { used is Brown's Double Exponential Smoothing. This study aims to explain } \\
\text { the application of themethod Brown's Double Exponential Smoothing in } \\
\text { forecasting the inflation rate in Indonesia, determine the optimum parameter } \\
\text { value and determine the level of accuracy of the forecasting results. This } \\
\text { study takes inflation data from the official website of Bank Indonesia. } \\
\text { Forecasting steps using themethod, Brown's namely determining the optimum } \\
\text { parameter value, calculating thesingle smoothingvalue, calculating the value } \\
\text { ofdouble smoothing, calculating the smoothing constant value, calculating the } \\
\text { value of thecoefficient trend, then doing the forecast. Based on the calculation } \\
\text { onmethod Brown's, the optimum parameter value is alpha ( } \alpha) \text { of } 0.9 \text { with a } \\
\text { MAPE value of } 10.607 \% \text {. From forecasting calculations using themethod } \\
\text { Brown's, the error value is obtained, namely MAPE of } 10.607 \% \text {, which } \\
\text { means that themethod Brown's has a good ability in forecasting according to } \\
\text { the MAPE criteria. }\end{array}$ \\
\hline & This is an open access article under the CC-BY-SA license. \\
\hline
\end{tabular}




\section{PENDAHULUAN}

Mayoritas masyarakat Indonesia merasakan bahwa harga barang dan jasa kebutuhan pokok pada saat ini lebih mahal dibandingkan dengan satu atau dua tahun yang lalu. Kenaikan harga-harga kebutuhan pokok dari waktu ke waktu tersebut disebabkan karena adanya inflasi. Inflasi merupakan kecenderungan (trend) naiknya harga barang dan jasa secara umum yang berlangsung terus menerus[1]. Jika harga barang dan jasa di dalam negeri meningkat, maka inflasi mengalami kenaikan. Hal tersebut menyebabkan turunnya nilai mata uang. Dengan demikian, inflasi dapat juga diartikan sebagai penurunan nilai mata uang terhadap nilai suatu barang dan jasa secara umum. Dengan menurunnya nilai mata uang, maka kemampuan masyarakat dalam membeli barang dan jasa kebutuhan sehari-hari akan menjadi semakin sulit dan rendah.

Inflasi yang rendah dan terkendali dapat mendukung terpeliharanya daya beli masyarakat, inflasi yang tinggi menyebabkan pendapatan masyarakat akan terus turun dan inflasi yang tidak stabil akan mempersulit dunia usaha dalam perencanaan kegiatan bisnis, baik dalam kegiatan produksi dan investasi maupun dalam penentuan harga barang dan jasa yang diproduksinya serta berbagai dampak negatif lain yang tidak kondusif bagi perekonomian secara keseluruhan. Maka diperlukan peramalan untuk memprediksi inflasi yang akan datang agar para pelaku usaha dapat melakukan perencanaan yang matang dalam melakukan kegiatan usahanya dan supaya masyarakat dapat memperkirakan strategi yang sesuai dalam melakukan konsumsi dan investasi.

Peramalan (forecasting) merupakan upaya untuk memprediksi masa depan berdasarkan metode ilmiah (sains dan teknologi) secara sistematis dengan perhitungan yang objektif menggunakan datadata bulan atau tahun sebelumnya. Tujuan lain dari forecasting adalah untuk mendapatkan peramalan yang bisa meminimalkan kesalahan meramal (forecast error) yang diukur menggunakan Mean Absolute Error (MAE) dan Mean Squared Error (MSE) dan yang lainnya [2]. Dalam deret berkala (time series) dengan pola data memuat trend, metode yang sering digunakan untuk peramalan ialah metode pemulusan exponensial (exponential smoothing).

Metode Exponential Smoothing adalah metode yang mengulang perhitungan secara terusmenerus menggunakan data masa lalu terbaru berdasarkan perhitungan rata-rata penghalusan secara exponensial[3]. Dalam Exponential Smoothing metode yang sesuai dengan data yang memuat trend yaitu Pemulusan Eksponensial Ganda (Double Exponential Smoothing) dalam hal ini yaitu metode Brown's Double Exponential Smoothing. Brow's DES merupakan model linear yang dikemukakan oleh Brown, yaitu metode dengan penambahan nilai pemulusan ganda untuk nilai-nilai pemulusan tunggal serta hanya menggunakan satu parameter.

\section{METODE}

\section{Analisis Deret Waktu}

Data deret waktu (time series) merupakan data yang dikumpulkan dan dicatat dalam periode waktu tertentu[4]. Data time series dianalisis untuk menemukan pola variansi masa lalu yang dapat dipergunakan untuk memperkirakan nilai untuk masa depan (forecast). Analisis deret waktu merupakan metode yang digunakan untuk mempelajari deret waktu, baik dari segi materi maupun peramalan. Analisis deret waktu pertama diperkenalkan oleh Brown [5] pada tahun 1970 melalui bukunya yang bejudul Time Series Analysis : Forecasting and Control. Terdapat beberapa asumsi penting yang harus dipenuhi agar data deret waktu dapat digunakan dalam peramalan, yaitu :

a. Adanya hubungan (korelasi) antara kejadian pada masa yang akan datang terhadap masa sebelumnya.

b. Aktivitas pada masa mendatang mengikuti pola yang terjadi pada masa lalu dan hubungan/keterkaitan pada masa lalu dapat ditentukan dengan pengamatan atau penelitian.

\section{Pemulusan Eksponensial (Exponential Smoothing)}

Metode Exponential Smoothing adalah metode yang mengulang perhitungan secara terus-menerus menggunakan data masa lalu terbaru berdasarkan perhitungan rata-rata penghalusan secara exponensial[6]. Menurut Arsyad [7] metode exponential smoothing dipergunakan secara luas untuk peramalan dikarenakan memiliki beberapa keunggulan, seperti memberikan ketepatan dalam ramalan jangka pendek, mudah disesuaikan dengan perubahan data, dan tidak membutuhkan banyak data. Dalam kategori ini terdapat beberapa metode antara lain metode Single Exponential Smoothing, 
Double Exponential Smoothing dari Brown dan Holt dan Triple Exponential Smoothing. Semuanya mempunyai sifat yang sama yaitu nilai yang lebih baru diberikan bobot yang relatif lebih besar dibanding nilai pengamatan yang lebih lama [4]. Bobotnya dilambangkan dengan $\alpha$ (alpha) dan bergerak antara 0 sampai 1 . Bobot $\alpha$ untuk data yang paling kini, ( $1-\alpha)$ untuk data yang lebih kini berikutnya, dan (1- $\alpha) 2$ untuk data yang berikutnya, dan seterusnya [8].

3. Metode Pemulusan Eksponensial Ganda dari Brown (Brown's Double Exponential Smoothing)

Brown's Double Exponential Smoothing merupakan model linear yang dikemukakan oleh Brown, yaitu metode dengan penambahan nilai pemulusan ganda untuk nilai-nilai pemulusan tunggal serta hanya menggunakan satu parameter[9][10]. Metode ini digunakan ketika data menunjukkan adanya trend dan tidak memperhitungkan komponen musiman[11]. Rumus yang dipakai dalam implementasi brown's double exponential smoothing ditunjukkan di bawah ini [12]:

a. Menghitung nilai pemulusan tunggal (single smoothing)

$$
S^{\prime}{ }_{t}=\alpha X_{t}+(1-\alpha) S_{t-1}^{\prime}
$$

b. Menghitung nilai pemulusan ganda (double smoothing)

$$
S^{\prime \prime}{ }_{t}=\alpha{S^{\prime}}_{t}+(1-\alpha) S^{\prime \prime}{ }_{t-1}
$$

c. Menentukan nilai konstanta pemulusan

$$
a_{t}=2 S^{\prime}{ }_{t}-S^{\prime \prime}{ }_{t}
$$

d. Menentukan nilai koefisien trend

$$
b_{t}=\frac{\alpha}{1-\alpha}+\left(S_{t}^{\prime}-S^{\prime \prime}{ }_{t}\right)
$$

e. Melakukan peramalan

$$
F_{t+m}=a_{t}+b_{t}(m)
$$

dimana :

$S_{t}^{\prime} \quad$ : Nilai pemulusan tunggal

$S^{\prime \prime}{ }_{t} \quad$ : Nilai pemulusan ganda

$a_{t} \quad:$ Nilai konstanta pemulusan pada periode $\mathrm{t}$

$b_{t} \quad:$ Nilai koefisien trend pada periode $\mathrm{t}$

$\alpha \quad$ : Parameter pemulusan dimana $0<\alpha<1$

$m \quad$ : Jumlah periode ke depan yang akan diramalkan

$F_{t+m} \quad:$ Peramalan ke- $m$ periode

4. Pemilihan Parameter $\alpha$ Optimum

Ketepatan metode peramalan dilihat dari kesalahan peramalan. Kesalahan peramalan merupakan ukuran ketepatan suatu peramalan. Dalam penelitian ini digunakan Mean Absolute Percentage Error (MAPE) untuk mengetahui ketepatan peramalan.

$$
M A P E=\frac{100 \%}{n} \sum_{t=1}^{n}\left|\frac{X_{t}-F_{t+m}}{X_{t}}\right|
$$

Semakin kecil nilai MAPE berarti nilai taksiran semakin mendekati nilai sebenarnya. Metode yang digunakan dalam penelitian ini yaitu Brown's Double Exponential Smoothing, sehingga nilai MAPE ini digunakan untuk mencari parameter $\alpha$ optimum dengan cara trial and error dengan bantuan software komputer. Nilai yang diperoleh dari evaluasi ini menunjukkan kemampuan dalam peramalan, seperti yang ditunjukkan dalam kriteria MAPE pada Tabel 2.1 [13] 
Tabel 1. Kriteria MAPE

\begin{tabular}{cl}
\hline MAPE & Kategori Kemampuan Peramalan \\
\hline$<10 \%$ & Sangat Baik \\
$10 \%-20 \%$ & Baik \\
$20 \%-50 \%$ & Cukup \\
$>50 \%$ & Buruk \\
\hline
\end{tabular}

5. Analisis Trend

Analisis trend merupakan suatu metode analisis yang digunakan untuk mengamati kecenderungan data secara menyeluruh pada suatu rentang waktu. Salah satu model yang dapat digunakan untuk menganalisis trend yaitu model linier. Trend linier adalah suatu trend yang pola nya cenderung turun atau naik secara linier. Model regresi linier sederhana untuk analisis trend adalah sebagai berikut :

$Y_{t}=\beta_{0}+\beta_{1} X_{t}+\varepsilon_{t}$

dimana $Y_{t}$ adalah nilai peubah tak bebas dalam pengamatan ke- t, $\beta_{0}$ dan $\beta_{1}$ adalah parameter, $X_{t}$ adalah konstanta yang diketahui dan $\varepsilon_{t}$ adalah galat. Apabila $b_{0}$ merupakan estimator untuk $\beta_{0}$ dan $b_{1}$ estimator untuk $\beta_{1}$ maka rumus untuk $b_{0}$ dan $b_{1}$ diturunkan menggunakan metode kuadrat terkecil yaitu dengan meminimumkan jumlah kuadrat galat. Sehingga diperoleh

$$
\begin{aligned}
& b_{0}=\frac{1}{n}\left(\sum_{t=1}^{n} Y_{t}-b_{1} \sum_{t=1}^{n} X_{t}\right) \\
& b_{1}=\frac{\sum_{t=1}^{n} X_{t} Y_{t}-\frac{1}{n} \sum_{t=1}^{n} X_{t} \sum_{t=1}^{n} Y_{t}}{\sum_{t=1}^{n} X_{t}^{2}-\frac{1}{n} \sum_{t=1}^{n} X_{t} \sum_{t=1}^{n} X_{t}}
\end{aligned}
$$

\section{HASIL DAN PEMBAHASAN}

Data inflasi yang digunakan diperoleh dari website resmi Bank Indonesia dari Januari 2014 sampai Mei 2019. Berikut adalah grafik untuk data inflasi tahun 2014-2019

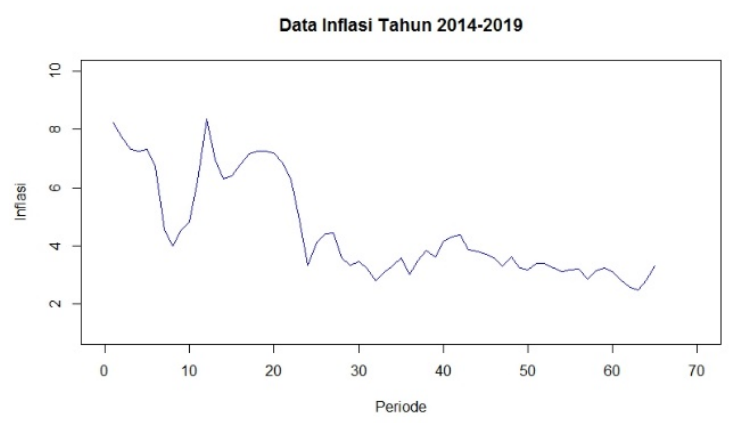

Gambar 1. Grafik Data Inflasi

Dari gambar tersebut dapat dilihat pola datanya. Namun, pada penelitian ini untuk menganalisis pola data dilakukan dengan menggunakan analisis trend.

Persamaan untuk analisis Trend secara umum yaitu

$\widehat{Y}_{t}=b_{0}+b_{1} X_{t}$

Diperoleh $b_{0}$ dan $b_{1}$ sebagai berikut

$b_{1}=\frac{\sum_{t=1}^{n} X_{t} Y_{t}-\frac{1}{n} \sum_{t=1}^{n} X_{t} \sum_{t=1}^{n} Y_{t}}{\sum_{t=1}^{n} X_{t}^{2}-\frac{1}{n} \sum_{t=1}^{n} X_{t} \sum_{t=1}^{n} X_{t}}=\frac{8051,36-\frac{1}{65}(294,09)(2145)}{93665-\frac{1}{65}(2145)(2145)}=-0,07227316$

$b_{0}=\frac{1}{n}\left(\sum_{t=1}^{n} Y_{t}-b_{1} \sum_{t=1}^{n} X_{t}\right)=\frac{1}{65}(294,09(-0,07227316)(2145))=6,909476$

diperoleh model linier untuk data inflasi yaitu $\widehat{Y_{t}}=6,909476-0,07227316 X_{t}$. Dengan mensubstitusikan $X_{t}=1,2, \ldots, 65$ maka diperoleh hasil estimasi data seperti pada grafik berikut 
Jurnal Ilmiah Matematika, 6 (2), 2019 - 58

Dini Purwanti, Joko Purwadi

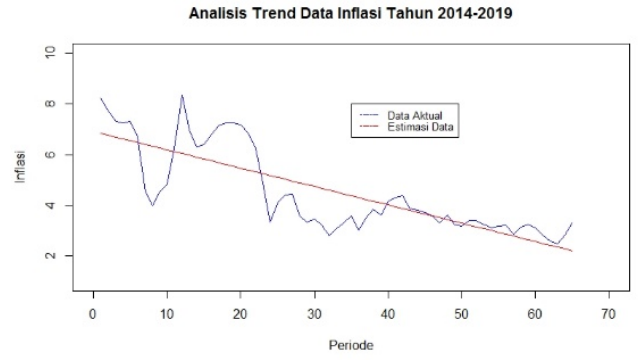

Gambar 2. Analisis Trend

Dari gambar tersebut dapat dilihat bahwa data yang digunakan memiliki pola data trend yang menurun.

Pemilihan parameter yang tepat akan mempengaruhi hasil peramalan beberapa periode kedepan. Parameter optimum ditentukan menggunakan cara trial and error dan dengan bantuan program komputer IBM SPSS 25. Hasil yang diperoleh dapat dilihat pada gambar berikut

Tabel 2. Parameter Optimum

\begin{tabular}{ccccccccccc}
\hline & \multicolumn{10}{c}{ Peramalan } \\
\cline { 2 - 11 } Periode & Data & $\boldsymbol{\alpha}=\mathbf{0 , 1}$ & $\boldsymbol{\alpha}=\mathbf{0 , 2}$ & $\boldsymbol{\alpha}=\mathbf{0 , 3}$ & $\boldsymbol{\alpha}=\mathbf{0 , 4}$ & $\boldsymbol{\alpha}=\mathbf{0 , 5}$ & $\boldsymbol{\alpha}=\mathbf{0 , 6}$ & $\begin{array}{c}\boldsymbol{\alpha}= \\
\mathbf{0 , 7}\end{array}$ & $\boldsymbol{\alpha}=\mathbf{0 , 8}$ & $\boldsymbol{\alpha}=\mathbf{0 , 9}$ \\
\hline 1 & 8,22 & & & & & & & & & \\
2 & 7,75 & 8,22 & 8,22 & 8,22 & 8,22 & 8,22 & 8,22 & 8,22 & 8,22 & 8,22 \\
3 & 7,32 & 8,126 & 8,032 & 7,938 & 7,844 & 7,75 & 7,656 & 7,562 & 7,468 & 7,374 \\
4 & 7,25 & 7,960 & 7,728 & 7,525 & 7,350 & 7,202 & 7,084 & 6,993 & 6,930 & 6,896 \\
5 & 7,32 & 7,805 & 7,490 & 7,262 & 7,111 & 7,025 & 6,993 & 7,004 & 7,046 & 7,109 \\
$\vdots$ & $\vdots$ & $\vdots$ & $\vdots$ & $\vdots$ & $\vdots$ & $\vdots$ & $\vdots$ & $\vdots$ & $\vdots$ & $\vdots$ \\
65 & 3,32 & 2,720 & 2,622 & 2,601 & 2,623 & 2,684 & 2,773 & 2,877 & 2,985 & 3,087 \\
MAPE & & 15,966 & 12,355 & 11,251 & 11,279 & 11,082 & 10,721 & 10,681 & 10,720 & 10,607 \\
\hline
\end{tabular}

Dari tabel tersebut diperoleh nilai parameter optimum $\alpha$ sebesar 0,9 dengan nilai MAPE sebesar $10,607 \%$.

Setelah diperoleh nilai $\alpha$ optimum, selanjutnya dilakukan perhitungan peramalan.

1. Pemulusan tunggal (single smoothing)

Pemulusan tunggal dapat dihitung menggunakan persamaan berikut

$S_{t}^{\prime}=\alpha X_{t}+(1-\alpha) S^{\prime}{ }_{t-1}$

Diperoleh

$S^{\prime}{ }_{1}=X_{1}=8,22$

$S^{\prime}{ }_{2}=\alpha X_{2}+(1-\alpha) S_{1}^{\prime}=0,9(7,75)+(1-0,9) 8,22=7,797$

$S^{\prime}{ }_{3}=\alpha X_{3}+(1-\alpha) S^{\prime}{ }_{2}=0,9(7,32)+(1-09) 7,797=7,368$

Dan seterusnya sampai pada perhitungan ${S^{\prime}}_{t}$ dengan $t=65$ yaitu sebagai berikut

$S_{65}^{\prime}=\alpha X_{65}+(1-\alpha) S_{64}^{\prime}=0,9(3,32)+(1-0,9) 2,796=3,268$

2. Pemulusan ganda (double smoothing)

Pemulusan ganda dapat dihitung menggunakan persamaan berikut $S^{\prime \prime}{ }_{t}=\alpha S^{\prime}{ }_{t}+(1-\alpha) S^{\prime \prime}{ }_{t-1}$

Diperoleh

$S^{\prime \prime}{ }_{1}=X_{1}=8,22$ 
$S^{\prime \prime}{ }_{2}=\alpha S^{\prime}+(1-\alpha) S^{\prime \prime}{ }_{1}=0,9(7,797)+(1-0,9) 8,22=7,839$

$S^{\prime \prime}{ }_{3}=\alpha S^{\prime}{ }_{3}+(1-\alpha) S^{\prime \prime}{ }_{2}=0,9(7,368)+(1-0,9) 7,839=7,415$

Dan seterusnya sampai pada perhitungan $S^{\prime}{ }_{t}$ dengan $t=65$ yaitu sebagai berikut $S^{\prime \prime}{ }_{65}=\alpha S_{65}^{\prime}+(1-\alpha) S^{\prime \prime}{ }_{64}=0,9(3,268)+(1-0,9) 2,767=3,218$

3. Konstanta pemulusan

Konstanta pemulusan dapat ditentukan menggunakan persamaan berikut

$$
a_{t}=2 S_{t}^{\prime}-S^{\prime \prime}{ }_{t}
$$

Diperoleh

$a_{1}=2 S^{\prime}{ }_{1}-S^{\prime \prime}{ }_{1}=2(8,22)-8,22=8,22$

$a_{2}=2 S^{\prime}{ }_{2}-S^{\prime \prime}{ }_{2}=2(7,797)-7,839=7,755$

$a_{3}=2 S^{\prime}{ }_{3}-S^{\prime \prime}{ }_{3}=2(7,368)-7,415=7,321$

Dan seterusnya sampai pada perhitungan $a_{t}$ dengan $t=65$ yaitu sebagai berikut

$a_{65}=2 S_{65}^{\prime}-S^{\prime \prime}{ }_{65}=2(3,268)-3,218=3,318$

4. Koefisien Trend

Nilai koefisien trend dapat ditentukan dengan persamaan berikut

$b_{t}=\frac{\alpha}{1-\alpha}+\left(S^{\prime}{ }_{t}-S^{\prime \prime}{ }_{t}\right)$

Diperoleh

$b_{1}=\frac{\alpha}{1-\alpha}+\left(S_{1}^{\prime}-S^{\prime \prime}{ }_{1}\right)=\frac{0,9}{1-0,9}+(8,22-8,22)=0$

$b_{2}=\frac{\alpha}{1-\alpha}+\left(S^{\prime}{ }_{2}-S^{\prime \prime}{ }_{2}\right)=\frac{0,9}{1-0,9}+(7,797-7,839)=-0,381$

$b_{3}=\frac{\alpha}{1-\alpha}+\left(S^{\prime}{ }_{3}-S^{\prime \prime}{ }_{3}\right)=\frac{0,9}{1-0,9}+(7,368-7,415)=-0,424$

Dan seterusnya sampai pada perhitungan $b_{t}$ dengan $t=65$ yaitu sebagai berikut

$b_{65}=\frac{\alpha}{1-\alpha}+\left(S_{65}^{\prime}-S_{65}^{\prime \prime}\right)=\frac{0,9}{1-0,9}+(3,268-3,218)=0,450$

5. Perhitungan Peramalan

Untuk melakukan peramalan pada metode brown's digunakan persamaan berikut

$F_{t+m}=a_{t}+b_{t}(m)$

Dengan $m$ merupakan jumlah periode. Diperoleh

$F_{1+1}=a_{1}+b_{1}(1)=8,22+0=8,22$

$F_{2+1}=a_{2}+b_{2}(1)=7,755-0,381=7,374$

$F_{3+1}=a_{3}+b_{3}(1)=7,320-0,424=6,896$

Dan seterusnya sampai pada perhitungan $F_{t+m}$ dengan $t=64$ yaitu sebagai berikut

$F_{64+1}=a_{64}+b_{64}(1)=2,825+0,262=3,087$

Akan dilakukan peramalan untuk 3 periode kedepan, sehingga diperoleh

$F_{65+1}=a_{65}+b_{65}(1)=3,318+0,450(1)=3,768$

$F_{65+2}=a_{65}+b_{65}(2)=3,318+0,450(2)=4,219$

$F_{65+3}=a_{65}+b_{65}(3)=3,318+0,450(3)=4,669$

Untuk menghitung nilai eror dalam peramalan, digunakan MAPE sebagai berikut

$$
M A P E=\frac{100 \%}{n} \sum_{t=1}^{n}\left|\frac{X_{t}-F_{t+m}}{X_{t}}\right|
$$

diperoleh

$$
M A P E=\frac{100 \%}{65} \sum_{t=1}^{65}\left|\frac{X_{t}-F_{t+m}}{X_{t}}\right|=\frac{100 \%}{65} \sum_{t=1}^{65}|6,894|=10,607 \%
$$

Berikut adalah keseluruhan data hasil dari peramalan menggunakan metode Brown 
Jurnal Ilmiah Matematika, 6 (2), 2019 - 60

Dini Purwanti, Joko Purwadi

Tabel 3. Hasil Perhitungan Peramalan Menggunakan Metode Brown

\begin{tabular}{|c|c|c|c|c|c|c|c|}
\hline Periode & $X_{t}$ & $S_{t}^{\prime}$ & $S^{\prime \prime}{ }_{t}$ & $a_{t}$ & $b_{t}$ & $F_{t+m}$ & MAPE \\
\hline 1 & 8,22 & 8,22 & 8,22 & 8,22 & 0 & & \\
\hline 2 & 7,75 & 7,797 & 7,8393 & 7,7547 & $-0,3807$ & 8,22 & 0,060645161 \\
\hline 3 & 7,32 & 7,3677 & 7,41486 & 7,32054 & $-0,42444$ & 7,374 & 0,007377049 \\
\hline 4 & 7,25 & 7,26177 & 7,277079 & 7,246461 & $-0,137781$ & 6,8961 & 0,048813793 \\
\hline 5 & 7,32 & 7,314177 & 7,3104672 & 7,3178868 & 0,0333882 & 7,10868 & 0,028868852 \\
\hline 6 & 6,70 & 6,7614177 & 6,81632265 & 6,70651275 & $-0,494144$ & 7,351275 & 0,097205224 \\
\hline 7 & 4,53 & 4,75314177 & 4,959459858 & 4,546823682 & $-1,8568628$ & 6,2123682 & 0,371383709 \\
\hline 8 & 3,99 & 4,066314177 & 4,155628745 & 3,976999609 & $-0,8038311$ & 2,68996089 & 0,325824338 \\
\hline 9 & 4,53 & 4,483631418 & 4,45083115 & 4,516431685 & $-0,2952024$ & 3,173168496 & 0,299521303 \\
\hline 10 & 4,83 & 4,795363142 & 4,760909943 & 4,829816341 & 0,3100788 & 4,81163409 & 0,003802466 \\
\hline$\vdots$ & $\vdots$ & $\vdots$ & $\vdots$ & $\vdots$ & $\vdots$ & $\vdots$ & $\vdots$ \\
\hline 64 & 2,83 & 2,796181905 & 2,767092474 & 2,825271337 & 0,261804884 & 2,357133674 & 0,167090575 \\
\hline 65 & 3,32 & 3,267618191 & 3,217565619 & 3,317670762 & 0,450473145 & 3,087076221 & 0,070157765 \\
\hline$\sum$ & & & & & & & 6,894281677 \\
\hline Mean & & & & & & & 0,106065872 \\
\hline
\end{tabular}

\section{SIMPULAN}

1. Metode Brown's Double Exponential Smoothing (B-DES) merupakan model linear dengan penambahan nilai pemulusan ganda untuk nilai-nilai pemulusan tunggal serta hanya menggunakan satu parameter. Metode ini digunakan ketika data menunjukkan adanya trend dan tidak memperhitungkan komponen musiman. Persamaan yang digunakan dalam implementasi metode Brown's ialah sebagai berikut[12]:
a) Menghitung nilai pemulusan tunggal (single smoothing) $S_{t}^{\prime}=\alpha X_{t}+(1-\alpha) S_{t-1}^{\prime}$
b) Menghitung nilai pemulusan ganda (double smoothing) $S^{\prime \prime}{ }_{t}=\alpha S_{t}^{\prime}+(1-\alpha) S^{\prime \prime}{ }_{t-1}$
c) Menentukan nilai konstanta pemulusan $a_{t}=2 S^{\prime}{ }_{t}-S^{\prime \prime}{ }_{t}$
d) Menentukan nilai koefisien trend $b_{t}=\frac{\alpha}{1-\alpha}+\left(S^{\prime}{ }_{t}-S^{\prime \prime}{ }_{t}\right)$

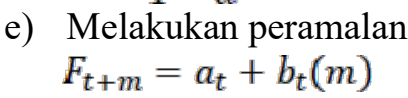

dimana $m$ adalah jumlah ramalan periode ke depan. Agar rumus tersebut dapat digunakan, maka nilai $S_{t-1}^{\prime}$ dan $S^{\prime \prime}{ }_{t-1}$ harus tersedia. Tetapi pada saat $\mathrm{t}=1$ nilai-nilai tersebut tidak tersedia. Karena nilai-nilai ini harus ditentukan pada awal periode, untuk mengatasi masalah ini dapat dilakukan dengan menetapkan $S_{1}^{\prime}$ dan $S^{\prime \prime}{ }_{1}$ sama dengan nilai $X_{1}$ (data aktual)[12]. 
2. Berdasarkan perhitungan pada metode Brown untuk menentukan parameter optimum dengan bantuan program komputer dan dengan melihat nilai MAPE diperoleh nilai parameter optimum yaitu alpha $\alpha$ sebesar 0,9 dengan nilai MAPE sebesar 10,607\%.

3. Evaluasi hasil peramalan digunakan untuk mengetahui keakuratan hasil dari peramalan yang telah dilakukan karena setiap metode peramalan pasti menghasilkan kesalahan. Semakin kecil tingkat kesalahan yang dihasilkan, maka peramalan yang dihasilkan semakin baik atau semakin mendekati tepat. Pada penelitian ini, peramalan yang telah dilakukan menghasilkan nilai kesalahan yaitu MAPE sebesar 10,607\% yang berarti bahwa metode Brown's mempunyai kemampuan yang baik dalam peramalan sesuai dengan kriteria MAPE.

\section{DAFTAR PUSTAKA}

[1] A. Ma'ruf and L. Wihastuti, "Pertumbuhan ekonomi indonesia: determinan dan prospeknya," $J$. Ekon. Stud. Pembang., vol. 9, no. 1, pp. 44-55, 2008.

[2] P. Subagyo, "Forecasting, Konsep dan Aplikasi, Yogyakarta," Ed. Keempat, BPFE UGM, 2002.

[3] S. Ghosh and S. K. Dubey, "Comparative analysis of k-means and fuzzy c-means algorithms," Int. J. Adv. Comput. Sci. Appl., vol. 4, no. 4, 2013.

[4] N. S. Muhamad and A. Mohamed Din, "Exponential smoothing techniques on time series river water level data," 2015.

[5] R. G. Brown, "Smoothing, Forecasting and Prediction, Prentice-Hall, Englewood Cliffs," 1963.

[6] E. O. Noeryanti and F. Andriyani, "Aplikasi pemulusan eksponensial dari brown dan dari holt untuk data yang memuat trend," in Seminar Nasional Aplikasi Sains \& Teknologi (SNAST) Periode III, 2012, pp. 447-455.

[7] L. Arsyad, "Peramalan bisnis," BPFE-Yogyakarta. Yogyakarta, 2001.

[8] L. R. Aritonang and R. Lerbin, "Peramalan bisnis," Ghalia Indones. Jakarta, 2002.

[9] Z. Inayah, "Perbandingan Metode Holt dan Brown pada Double Exponential Smoothing (Peramalan Jumlah Kejadian TB Paru).” UNIVERSITAS AIRLANGGA, 2010.

[10] M. Mansyur and E. Rohadi, "Sistem Informasi Peramalan Stok Barang Di CV. Annora Asia Menggunakan Metode Double Exponential Smoothing," J. Inform. Polinema, vol. 2, no. 1, p. 45, 2015.

[11] E. Pujiati, D. Yuniarti, and R. Goejantoro, "Peramalan Dengan Menggunakan Metode Double Exponential Smoothing Dari Brown," J. Eksponensial, vol. 7, no. 1, pp. 33-40, 2017.

[12] S. Makridakis, S. C. Wheelwright, and V. E. McGee, "Metode dan aplikasi peramalan," Jakarta: Erlangga, 1999.

[13] P.-C. Chang, Y.-W. Wang, and C.-H. Liu, "The development of a weighted evolving fuzzy neural network for PCB sales forecasting," Expert Syst. Appl., vol. 32, no. 1, pp. 86-96, 2007. 